\title{
Data Management of Proxy Parameters with PANGAEA
}

\author{
M. Diepenbroek ${ }^{1}$, H. Grobe ${ }^{2 *}$, M. Reinke ${ }^{2}$, R. Schlitzer ${ }^{2}$ and R. Sieger ${ }^{2}$ \\ ${ }^{I}$ MARUM Zentrum für Marine Umweltwissenschaften, Universität Bremen, \\ Postfach 33 04 40, D-28334 Bremen, Germany \\ ${ }^{2}$ Alfred-Wegener-Institut für Polar-und Meeresforschung, Postfach 1201 61, \\ D-27515 Bremerhaven, Germany \\ *corresponding author (e-mail):info@pangaea.de
}

\begin{abstract}
Specific parameters determined from marine sediments can be used as proxy data to calculate former ocean properties. To use this scientific resource effectively an information system is needed which guarantees consistent longtime storage of the proxy data and provides easy access for the scientific community. An information system to archive proxy data of paleoclimatic relevance, together with the related meta-information, raw data and evaluated paleoclimatic data, is presented here. The system provides standardized import and export routines, easy access with uniform retrieval functions, and tools for the visualization of data. The network is designed as a client/server system providing access through the Internet.
\end{abstract}

\section{Introduction}

Paleoclimate data are important because they extend the baseline of environmental and climatic observations back into the geological past. The library of natural climatic archives is the best means of determining how the climatic system operated under boundary conditions substantially different from today. An understanding of the past is essential in modeling future climate development and environmental changes.

Data relating to previous environmental conditions are available from instrumental records and documentary history, in addition to various natural paleoclimatic archives. These include continental ice, marine, lakustrine and terrestrial sediments, cave spelaeothems, tree rings and corals. The archives provide records of time spans ranging from years to millions of years, and resolutions ranging between months and thousands of years.

The oceans play a key part in understanding climate as they are the major sink for carbon dioxide. Reconstructing the oceanography of the past - namely, the field of 'paleoceanography' - is one major step in understanding the processes related to climatic change. The development of a technique to measure the isotopic composition of fossil plankton shells and to use these data for the reconstruction of the ice age climate (Emiliani 1955) started this fast-growing branch of marine geology. Five decades of research on marine sediments have clearly shown that this paleoclimatic archive contains a wealth of information about the most important parts of the climatic system: the hydrosphere and the kryosphere. Sediments provide a record covering about 140 million years. Since the invention of piston coring by Kullenberg, sediment cores have been recovered by various means to sample the uppermost layers $(<50 \mathrm{~m})$ of the ocean floor. Conventional drilling to recover long sediment sequences of up to several hundred of meters is being undertaken in the Deep Sea Drilling Project (DSDP) and the Ocean Drilling Program (ODP).

The samples taken from these cores are analyzed to reconstruct paleoceanographic conditions. A number of analytical parameters can be 


\begin{tabular}{|c|c|c|c|}
\hline parameter group & parameter & source & used as proxy for \\
\hline \multirow[t]{8}{*}{ microfossil assemblages } & $\%$ foraminifera species & planktonic foraminifera & sea surface temp., surface productivity \\
\hline & $\%$ foraminifera species & benthic foraminifera & oxygen in bottom water, export productivity \\
\hline & $\%$ coccoliths species & coccoliths & sea surface temp. \\
\hline & $\%$ radiolaria species & radiolaria & sea surface temp., export productivity \\
\hline & $\%$ diatom species & diatoms & sea surface temp., export productivity, sea ice distribution \\
\hline & $\%$ silicoflagellate species & silicoflagellates & sea surface temp., export productivity \\
\hline & $\%$ ostracod species & ostracods & sea surface temp., salinity \\
\hline & $\%$ pollen species & pollen & terrestrial vegetation \\
\hline \multirow[t]{6}{*}{ stable isotopes } & Oxygen, d180 & foraminifera & sea surface temp. \\
\hline & Carbon, d13C & foraminifera & utilization/regeneration of organic matter, productivity \\
\hline & Nitrogen, d15N & organic matter & nutrients, surface productivity \\
\hline & Strontium, $87 \mathrm{Sr} / 86 \mathrm{Sr}$ & sediment & seawater chemistry, continental weathering \\
\hline & Osmium, $1870 \mathrm{~s} / 1860 \mathrm{~s}$ & sediment & seawater chemistry, continental weathering \\
\hline & Boron & foraminifera & $\mathrm{pH}$ \\
\hline \multirow[t]{3}{*}{ radionuclides } & Lead, $210 \mathrm{~Pb}$ & sediment & particle flux/rain rate \\
\hline & Thorium, 230Th & sediment & particle flux/rain rate \\
\hline & Protactinium, 231Pa & sediment & particle flux/rain rate \\
\hline \multirow[t]{4}{*}{ biogenic compounds } & Organic carbon, TOC & sediment & $\mathrm{pCO} 2$, export productivity, terrestrial input \\
\hline & Calcium carbonate, $\mathrm{CaCO} 3$ & sediment & export productivity, history of carbonate compens. depth \\
\hline & Opal, SiO2 & sediment & export productivity \\
\hline & Biomarker, Uk37 & coccoliths & sea surface temp., pCO2, surface productivity \\
\hline \multirow[t]{10}{*}{ elements } & Rare earth elements & sediment & particle flux/rain rate \\
\hline & $\mathrm{Sr} / \mathrm{Ca}$ & corals & sea surface temp. \\
\hline & $\mathrm{Ge} / \mathrm{Si}$ & biogenous opal & nutrients, seawater chemistry, continental weathering \\
\hline & $\mathrm{Cd} / \mathrm{Ca}$ & foraminifera & nutrients \\
\hline & $\mathrm{Ba} / \mathrm{Ca}$ & foraminifera & alkalinity \\
\hline & Barium & barite/sediment & productivity \\
\hline & Vanadium & foraminifera & distribution of anoxic sediments \\
\hline & Uranium & foraminifera & carbon cycling in ocean/atmosphere \\
\hline & Phosphorus & sediment & nutrients, continental weathering \\
\hline & Iron/Manganese hydroxides & sediment & redox conditions \\
\hline \multirow{4}{*}{ sedimentology } & Ice rafted debris & sediment & activity of glaciers and continental ice sheets \\
\hline & Grain size distribution & sediment & velocity of bottom currents \\
\hline & Clay mineral assemblage & sediment & velocity and direction of bottom currents \\
\hline & Mineralogy & sediment & source of sediment, direction of transport \\
\hline
\end{tabular}

Table 1. List of parameters/parameter groups used as paleoclimatic proxy data for the reconstruction of paleoenvironmental conditions. All proxy parameters are defined in the PANGAEA parameter table, the import of data is organized by means of a unique parameter ID in the header of the matrix to be imported. 
determined from the samples. With the introduction of new and more efficient analytical methods the number of parameters and the amount of data obtained has increased by an order of magnitude during the last decade. Some of the parameters are the proxy data for the calculation of reconstructed ocean properties (e.g. paleotemperature, paleosalinity, paleoproductivity). Important parameters (Table 1) are the percentages of different species of microfossil assemblages, stable isotopes, radionuclides, the biogenic composition of a sediment or specific elements or elemental ratios. The results and data are published e.g. in the journal 'Paleoceanography' which is one of the first journals to require that authors store the relevant data in established databases (Webb et al. 1994).

The recovery and interpretation of proxy data related to the paleoclimate has traditionally been carried out by individuals or single laboratories, often examining regional records that cover a limited temporal domain. The emergence of an integrated earth systems science calls for a much fuller knowledge of the past, in both space and time, and for data sets that are drawn as composites from different methods and techniques. The only way to obtain a useful system for this purpose is to collect as many proxy data as possible, to store this data collection in a consistent format and to make it easily accessible to paleoceanographers. Tools for retrieving the data and for their visualization have to be closely linked to the collection. This proxy data collection, implemented in a network between working groups, can then be used as the data source as well as a common interpretation tool. In addition, geological proxy data which are used for the definition of ocean boundary conditions have to be used for model verification (Lorenz et al. 1996). In the future it could, and should, also be used as a publishing and reference system for data related to new publications to ensure that all the relevant data are stored in the same system.

In 1993, scientists from various German research institutes working in the field of paleoceanography initiated a project in response to these needs. The goal was the implementation of an information system which would allow an overview of the sampling material available with the related meta-information, and which would store paleoceanographic data of any kind in a consistent form and make these data easy accessible to the scientific community. Tools for import/export, graphical presentation and complex retrievals need to be closely related to data collection. Based on the discussion and recommendations of this group, the information system PANGAEA (PaleoNetwork for Geological and Environmental Data) was developed at the Alfred Wegener Institute for Polar and Marine Research (AWI), financed by the German Ministry of Education, Science, Research and Technology (BMBF) as part of a three year project (1994-1997).

This paper gives an overview and a short description of the PANGAEA data model, the hardware and software needed, the network concept and also gives an introduction to the tools for visualizing data. The network is still in the stage of being established in the scientific community. Within the next two years up to 10 institutes will be connected together to form the first real network for data from research on the variability of climate and environments.

\section{System Description}

The most important generic aspects of PANGAEA are the quality and availability of the data as well as the high adaptability and effective use of the system. Data quality can be described in terms of the validity of methods and the precision and objectivity of measurements. It is not essential to have only excellent quality data sets, however, it is important that the quality can be estimated. The completeness of the meta-information, including, in particular, the analytical method and the reference where the data have been published first is crucial in the understanding of the analytical data. The user of a specific data set must be able to verify the data by reading the reference and thus to make a decision about the quality and usefulness of the data.

The manual quality check is supplemented by an evolving system of generic and parameter-specific validation routines. These routines are based on the definition of analytical methods and parameters, which requires a given standard unit, possible minimum and maximum values and the possible precision of the data. This information will be 
used by validation routines during the import to filter out suspect values, e.g. outliers.

To improve the data consistency, data sets can be stored at different levels of processing. The primary data, e.g. counts of a microfossil assemblage or weights of granulometric investigations, are the raw data for calculations and interpretations. Archiving the raw data allows future re-calibration or new interpretations of the data sets. The secondary data are those values calculated from the raw data, and in many cases are percentages or other units of concentration. The secondary data will usually be the proxy data for the evaluation of parameters describing past environmental conditions. Parameters evaluated from the secondary data (e.g. paleotemperatures) are defined as tertiary data. With the definition of a tertiary parameter obtained from the proxy data, a method and reference can be given where the formula or method is published.

PANGAEA also ensures that the copyright is considered. If an information system also stores unpublished data, it is crucial for the acceptance and the trust of the database that the data are protected by a hierarchical system which can be organized and controlled by the user. The owner of a specific data set is the principal investigator, who is able to either define access rights to individual users/groups or to open data sets across the whole system. When using foreign data, the given reference has to be cited, thus giving a benefit to the data producers. For unpublished data the principal investigator has to be asked for permission to use the data.

The great variety of parameters, methods, calibrations and interpretations used in paleoenvironmental reconstruction, as well as the modification of established methods, are major obstacles to the integrative use of data sets in a common system. The challenge of managing these heterogenic and dynamic data was met in PANGAEA through a highly flexible data model consisting of a relational data structure in combination with specialized server software generating an object-oriented view of the data. This 'middle ware' is software to provide the link between clients and server. It transforms a logical request from a client into SQL or converts the resulting data from the server into a client readable format. Thus the middle ware allows the user to retrieve complex data matrices, e.g. time slices.

The simplified data structure of PANGAEA is shown as a graphic on the opening screen of the client software (Fig. 1). The graphic allows users to enter all levels, tables and tools by selecting the required field. The structure reflects the standard processing steps for paleo-data. Different institutes/projects (PROJECT) working in the field of paleoceanography carry out expeditions (CAMPAIGN) for sampling. During a cruise at a number of locations (SITE) different samples may be taken or measurements made (EVENT). At distinct points/intervals the medium to be investigated (e.g. sediment, water or ice) is sub-sampled or measured for different requirements. Information about the sampling procedure is stored at the SAMPLE level. Down to this level, all data are considered to be meta-data. From each sample one or more analytical data points will be produced which can be found on the DATA level, with the related meta-information (Fig. 2). Lists including standardized meta-information are connected to the main data table (e.g. gear, method). The parameters are gathered into parameter groups for a better overview and data are grouped as primary, secondary and tertiary data as described above - data types can be numerical, textual or pictures. The combination of the DATA, 'Parameter' and 'Method' table is the essential part of the model, which allows the definition and storage of new, unique parameters by the user at any time. From any table, data can be exported as tabulator delimited text files or plotted graphically. The possibility to configure the tables enables the user to extract data sets in a format needed for the import in commercial software or in his own programs.

The available meta-data comprises related information about expeditions, sampling sites/sets and storage facilities. In addition to the sampling/investigation site label, the most important meta-data are the location (latitude/longitude) and the elevation. For archiving profiles the definition of two locations/ elevations, including the date/time, is allowed. All scientists and institutes related to the data in the system are stored with their full addresses. Other related items, such as the names of ships, gears or sample types, are defined in lists which are regu- 
larly updated. The parameter list is organized in 26 groups and consists of about 2000 parameter definitions of different types. All the proxy parameters necessary for paleoceanography are included, together with their raw data and with the 'paleo-parameters' evaluated from the proxy data. Accessible from the EVENT field, the core description is stored as a graphic in an interchangeable format. Analytical methods can be defined with all the necessary information. References for cruise reports or published data can be typed in or imported from professional bibliography software.

In 1995, the NGDC/WDC-A published the prerelease of the Index to Marine Geological Samples on CD (Moore 1995). From this source the metadata of cores from six of the large core repositor- ies of the USA were extracted and imported into PANGAEA. Cores and samples from these repositories are used internationally and the analytical data were also stored in PANGAEA. Importing complete collections makes the import of analytical data much more efficient because the scientist does not have to consider any further metadata before importing analytical data from a specific core. The meta-data of sampling sites of paleoceanographic relevance also include all DSDP and ODP cores, the German core repositories, cores taken on French expeditions and sites of British, Norwegian and Russian research vessels. In 1997, PANGAEA comprised about 70000 sites of oceanic sampling, measurements and observations.

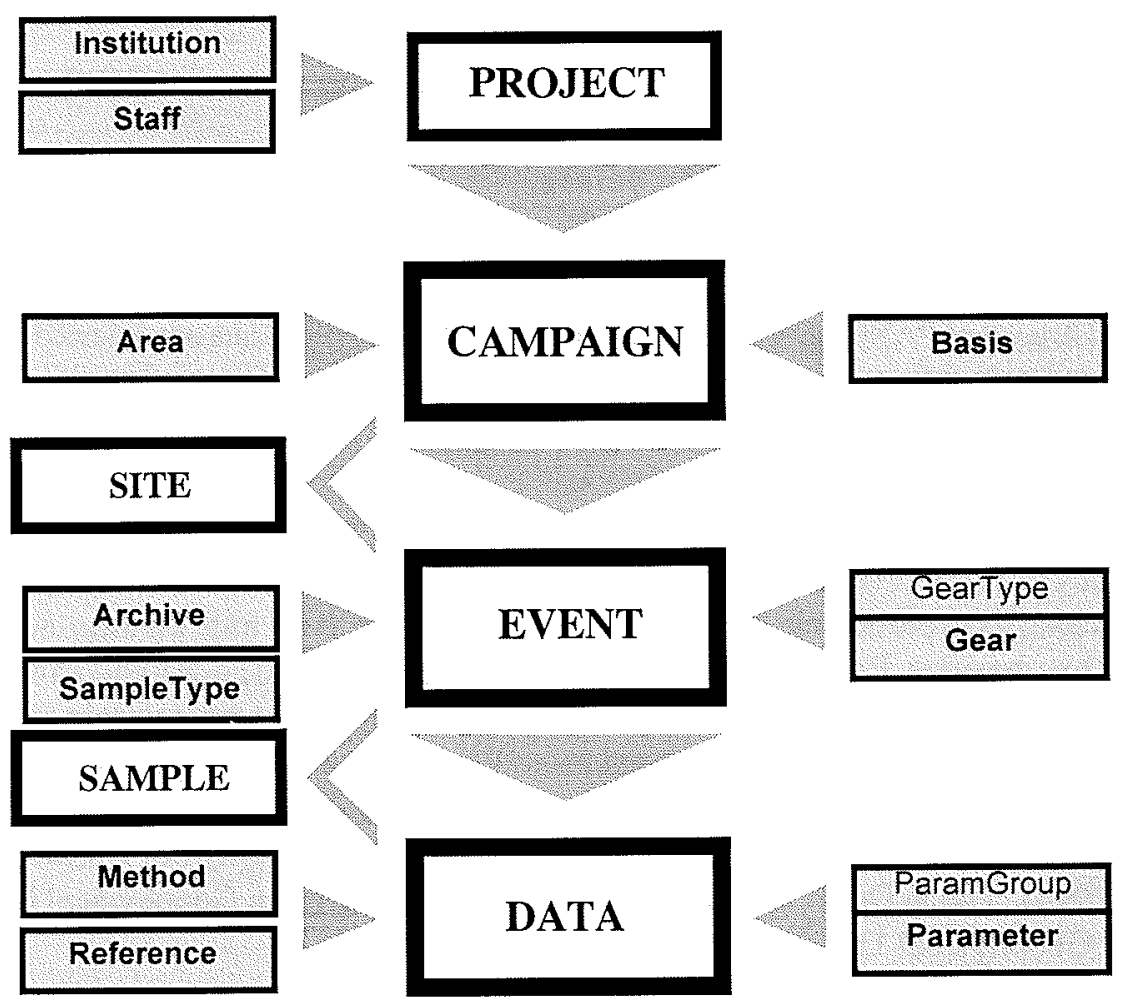

Fig. 1. The graphic shows the data model on the opening screen of PANGAEA. Each box indicates a table of information, arrows indicate relations between tables. The hierarchy follows the path from collecting samples to the final analytical/proxy/paleoenvironmental data. Within a PROJECT, different CAMPAIGNs are carried out to collect samples or measure environmental parameter at distinct SITEs with different EVENTs to obtain DATA. The model is universal and can be used for any scientific data which are oriented to a geographical site. The arrows show principle relations between tables. 


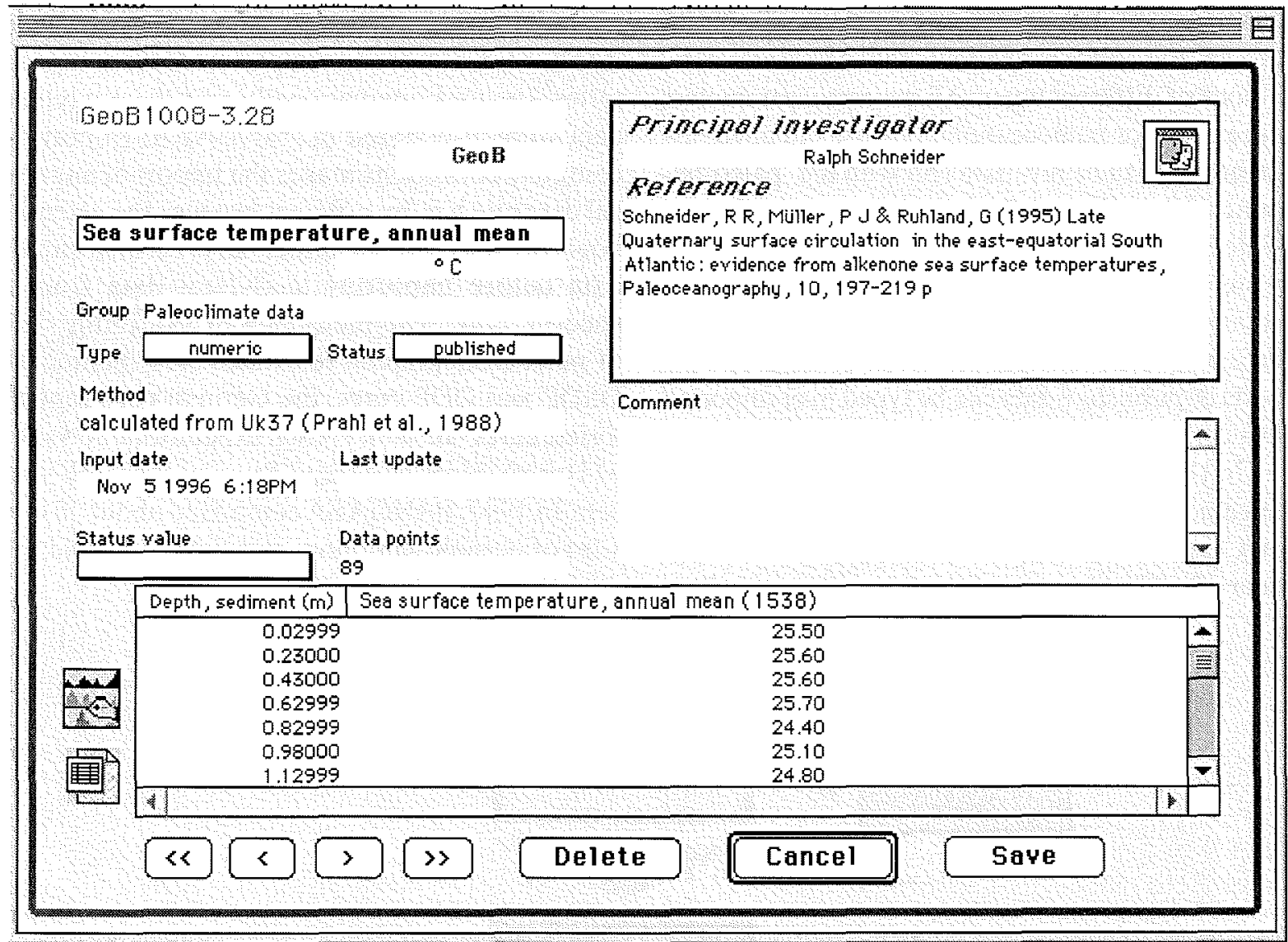

Fig. 2. The DATA level of PANGAEA provides the user with the analytical data of a selected data set in combination with all related meta-information necessary for understanding the data. The window also allows the definition of access rights, editing of the data and the export of data as text files or graphics.

It is the policy of PAGES (Past Global Changes) to encourage scientists to participate in international data banks. Thus besides PANGAEA there are other sources for proxy data available on the Internet. The major source for data from paleoclimatic research is the World Data Center-A for Paleoclimatology (WDC-A), established in 1992 (Webb et al. 1994). The WDC-A is located at the US. National Geophysical Data Center (NGDC) Paleoclimatology Program, Boulder, Colorado and is working with the IGBP/PAGES to coordinate a science-driven management system for the acquisition and distribution of all types of paleoenvironmental data. A first step in this process is to ensure that all published data are archived in a digital format and are available to the community. Data submitted to the center are organized on a ftp-server and are distributed via magnetic tape and on-line access via Internet (http://www.ngdc.noaa.gov/paleo/paleo.html). The most important proxy data available from the WDC-A are also accessible through PANGAEA as well as all data published in tables in the Journal 'Paleoceanography' or on the ftp-server of the AGU (American Geophysical Union).

\section{Network Concept, Hardware and Software}

PANGAEA uses client/server technology via the Internet to communicate between working groups (Fig. 3). The SQL-server (standard query language), running the database management software, is located in the computer center of the AWI and is connected through the Internet with the sub- 
servers of the various external institutes (remote sites) running the sub-server and front-end software. A number of clients, which are the personal computers of the scientists, can be connected through the local network to the sub-server of their related institute. To increase the access speed all meta-information is mirrored on each local subserver. The mutual update of newly imported metainformation is made in the background through the network between SQL-server and sub-servers. When clients are connected directly to the SQLserver, the meta-information is mirrored on the client itself. Access to the full functionality and the import of data is only possible through the frontend software. A web interface is provided to supply read-only access on all metadata and on analytical data with the status 'published' via the World Wide Web (http://www.pangaea.de).

As a first step, the main institutes working in the field of paleoceanography in Germany (GeologicalPalaeontological Institute, Kiel; GEOMAR, Kiel; Department of Geosciences, Bremen) were connected with the central PANGAEA server at the AWI. Further remote installations for other institutions in Germany and Europe are in progress. Tests of the client/server connections of PANGAEA through the Internet have shown that the transfer rates would allow the system to run in Europe with only one SQL-server.

The SQL-server is a DEC Alpha 8200 (four processors, $2 \mathrm{~GB}$ internal memory, $50 \mathrm{~GB}$ hard disk capacity) running SYBASE Version 11 under DEC/UNIX as the database management software. The client software for access to the server was written in 4th Dimension (4D, ACI); the WWW-client is a JAVA-applet. 4D has the opportunity to design a graphical user interface and allows optional compilation of the front-end software code for the two main operating systems found in personal computers (Macintosh OS, Windows).

The client software was modularized into a database front-end together with tools developed individually for processing specific data sets. The modularization and open environment facilitates the future adaptation of the system. The entry requirements for handling the software are low because the functionality is uniform for all tables and tools.
Updates of the 4D front-end software only have to be made on the sub-servers, so that the client software on the PCs is not affected by the update procedure.

The system requirements for running PANGAEA at an institute are an Internet connection and a fast Macintosh or Windows computer with at least $80 \mathrm{MB}$ of RAM, which has to be used for storing the mirrored meta-information. For sub-server systems, additional licenses for the 4D server software are needed, depending on the number of clients.

\section{PANGAEA Tools}

The import of meta-data is organized through predefined form tables which are available for the import of references, cruises, stations/sites and curatorial information. Analytical data are imported via simple tabulator delimited text tables with the name or the PANGAEA-ID of a specific parameter in the header of the input matrix. Meta-information related to the data (method, owner, comments) have to be defined before the import and are also updated during the import procedure.

The retrieval tool for finding and extracting data from the system is uniformly designed for all levels and allows the use of complex combinable search criteria relevant to the desired data. Data can be exported as tables or plotted with one of the graphics tools. Tables can be sorted and configured individually. Multiple data sets can either consist of different parameters, measured on one site or a single parameter from different sites; analytical data can be combined with any meta-data.

For the geographical presentation of data the PANGAEA tool PanMap was developed, which is either directly connected to the database frontend or can be used as a stand-alone application (Fig. 4). PanMap can be called directly by the user to draw sampling sites in a geographical context after selecting the required data set with the retrieval tool. Sites can be labeled with meta-data as well as analytical data. After calling PanMap from PANGAEA, the software is automatically started, data are exported from the database, imported by the mapping software and plotted in a default map. Maps can be configured with different projections, 


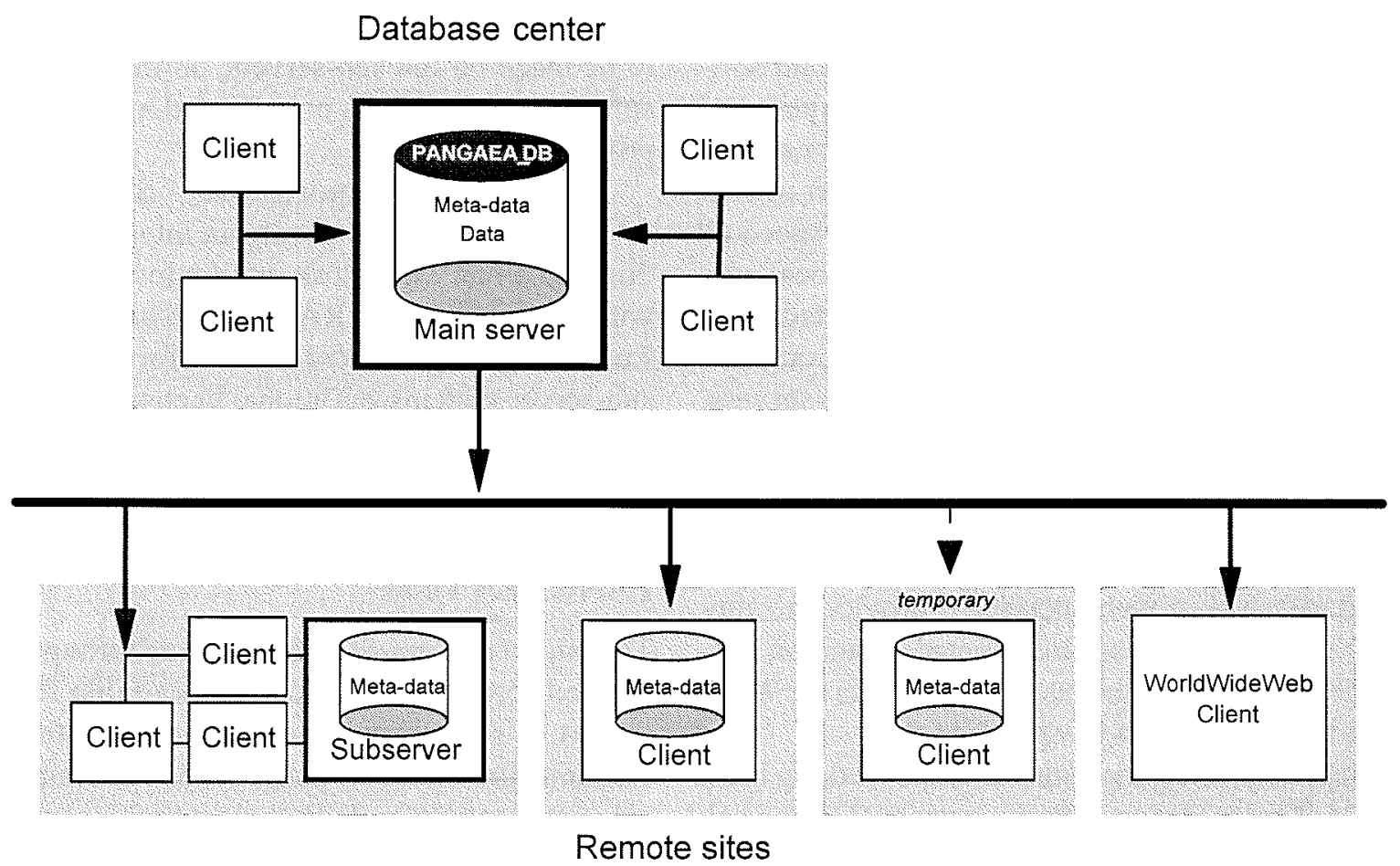

Fig. 3. The network concept of PANGAEA uses client/server technology through the Intranet/Internet to communicate between institutes/working groups. A remote site can be a group of clients using a subserver where all meta-data are mirrored, a single client directly connected with the main server, or a stand-alone version of the system with temporary connection to the network, e.g. for use on research vessels. Any of these clients will have full access to the functionality of the system. For retrieving published data from PANGAEA, a WWW interface is provided.

the styles of map elements can be changed, additional vector data or site information can be imported and maps can be exported. General Bathymetric Chart of the Oceans (GEBCO; IOC, 1994) can be used as the data source in the ocean maps. The data are provided at four different resolutions which can be used depending on the scale of the map. Tools are provided to digitize printed maps, the resulting output data as well as any individual elevation contours can be converted to the proprietary PanMap format.

The PANGAEA tool PanPlot has a similar link to the database as PanMap and allows the user to plot data versus depth/latitude or time (Fig. 5). Scales and graphic features can be modified by the user and distinct parameters can be selected from the data matrix, which has to be retrieved before the transfer. PanPlot graphs can be exported in platform-specific interchange formats.

Paleoceanographic research also requires access to the actual oceanographic data of the oceans. The National Oceanographic Data Center (NODC, Washington), provides these data in the World Ocean Atlas (WOA) 1994 (Levitus et al. 1995; Levitus an Boyer 1994) as one degree latitude-longitude mean fields for temperature, salinity, oxygen and nutrients at standard depth levels. The PANGAEA tool WOAccess allows access to these data sets from the EVENT and DATA level to obtain the oceanographic data closest to the site(s) of sampling. Data can be directly visualized with PanPlot. The WOA data set is also available in Ocean Data View (ODV) format.

Ocean Data View (Schlitzer 1997) is a software package for the visualization of oceanographic data 


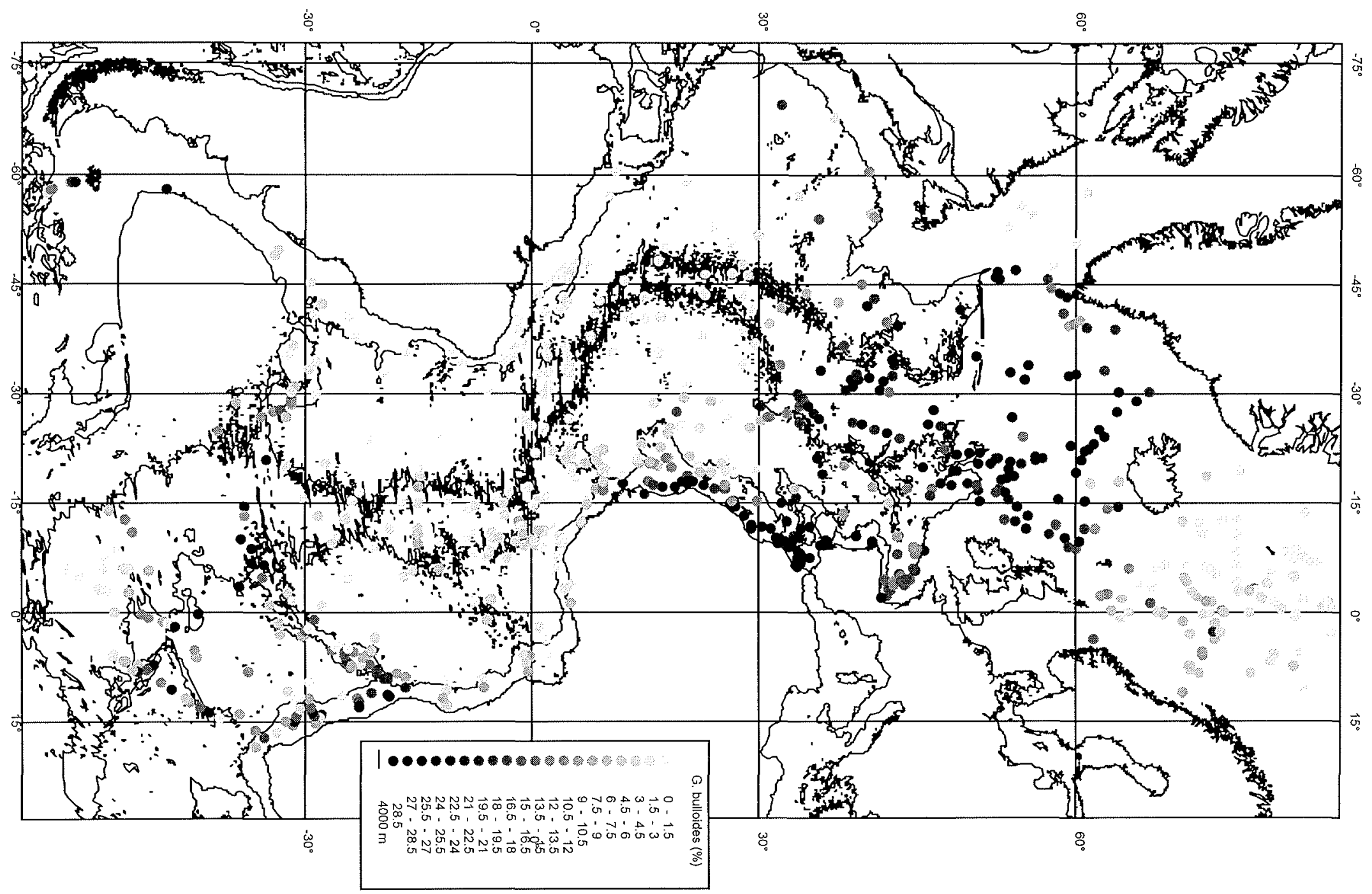

Fig. 4. For the presentation of data in geographical maps the PANGAEA tool PanMap was developed, which is either directly connected to the database frontend or used as a stand-alone application. PanMap can be called by PANGAEA to draw sampling sites labeled with meta-data or analytical data. The map shows sampling sites in the Atlantic where planktonic foraminifera were investigated in surface sediments (Pflaumann et al. 1996; Niebler 1995). The gray shading of dots is related to the percentage of a specific species (G. bulloides). The bathymetric data source is the General Bathymetric Chart of the Oceans (IOC, 1994). 


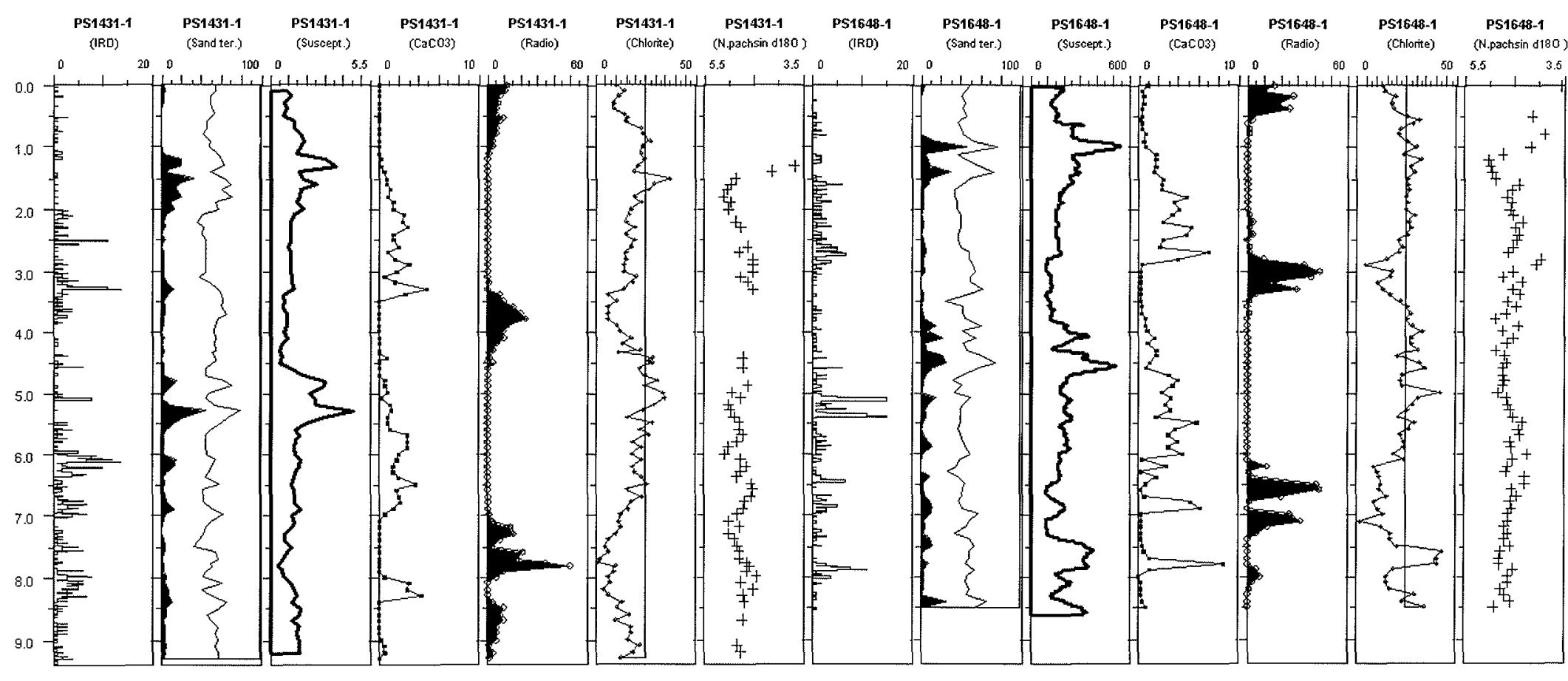

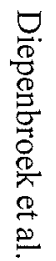

Fig. 5. The PANGAEA tool PanPlot enables the user to plot analytical data versus time or depth/latitude. PanPlot is a stand-alone running software, but can also be called by the database after retrieving a set of data. Scales and graphic features can be modified individually and distinct parameters can be selected from the data matrix. The example plot shows proxy parameters for ice rafting and the paleoproductivity of two sediment cores from the Antarctic continental margin covering the last two climatic cycles (Grobe and Mackensen 1992). 
on a Windows PC. The package can be used to create and manage large sets of proxy and (pale)oceanographic data and provides tools for easy exploration and the graphical display of these data as property/property plots, color sections and color distributions on isosurfaces (Fig. 6). The data collection format of ODV is optimized for dense storage and direct data access allowing the storage of large station collections on desktop computers. ODV can be called from PANGAEA after retrieving a data set which will then be exported in the format used by ODV.
A problem when importing meta-data is the inconsistency of using site labels and the different formats when reporting positions. A PANGAEA toolbox routine allows the conversion of any latitude/longitude format to that used by PANGAEA. After conversion of the position, the new sites can be compared with the contents of the database to determine duplicates or to look for alias labels.

The software used to calculate the parameters for paleoenvironmental reconstructions (e.g. paleotemperature) from proxy data (microfossil assemblages) with transfer functions (Imbrie and Kipp 1971) was converted for use on a Macintosh
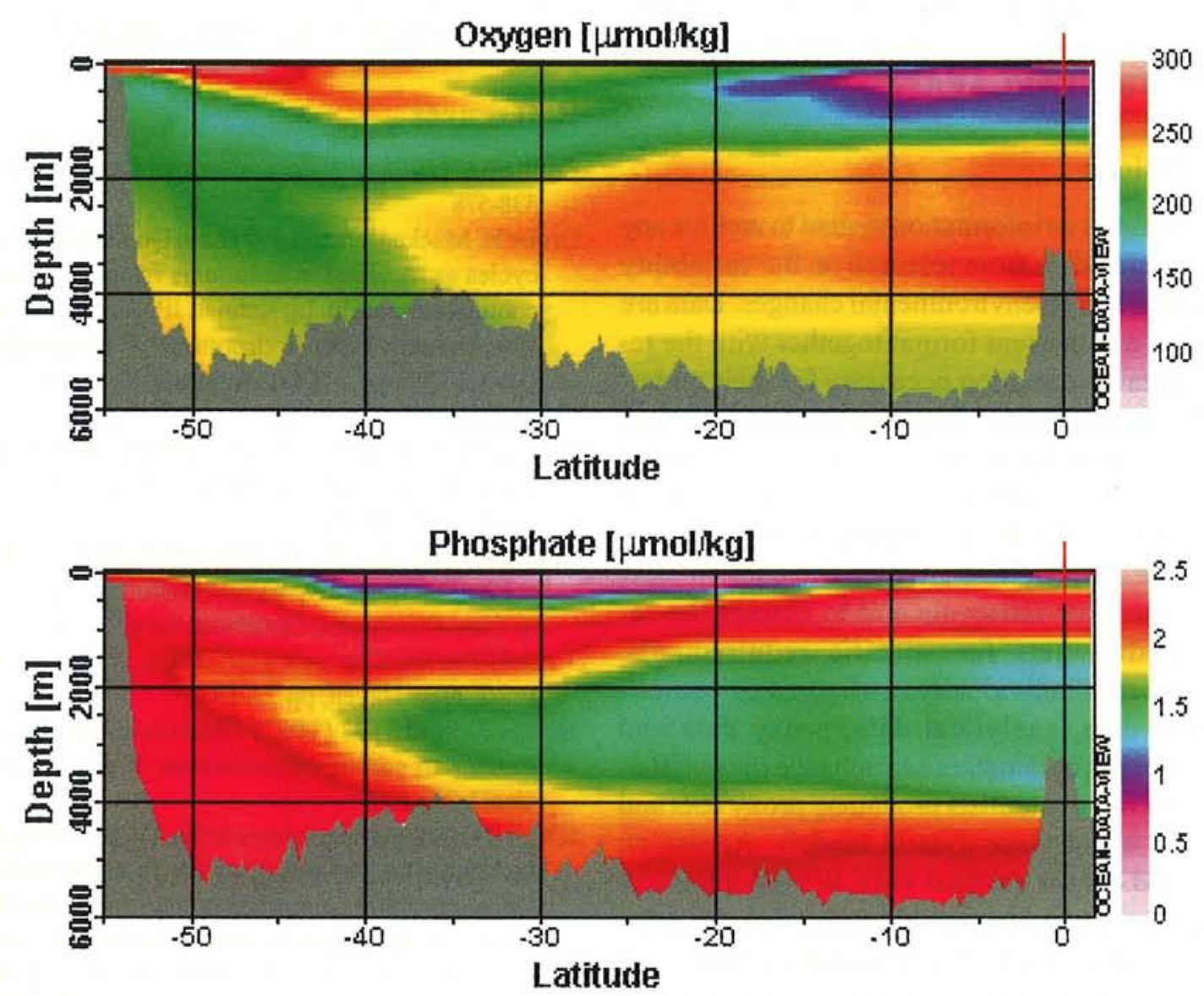

Fig. 6. The oceanographic software Ocean Data View (ODV), available on Windows platforms, can also be linked to PANGAEA. ODV draws data in depth/time slices or in sections. Simple interpolation routines are included in the software. In the sections given, the oxygen and phosphate concentrations are plotted along a N-S transect through the western South Atlantic. 
(MacTransfer). The file format used by MacTransfer to calculate the raw data is proprietary and thus not supported by the database. The preprocessor included in the PaleoTool routines converts the proxy data from a given microfossil assemblage into the import file format for MacTransfer. It is controlled via a 'project file' which can be assembled with the PaleoTools software. Export files can directly be processed with a spreadsheet software or PanPlot. The PaleoTools also allow microfossils to be counted with the aid of a computer keyboard. Another way to calculate paleoclimatic parameters from proxy data is the Modern Analog Technique (Imbrie and Purdy 1962; Houston 1980). The software MacMAT, as a further part of the PANGAEA tools, reads the proxy data and calculates, for example, paleotemperatures. The results can be read by spreadsheet software, plotted with PanPlot and imported into PANGAEA.

\section{Conclusions}

PANGAEA is an information system to archive any site-oriented data from research on the variability of climate and on environmental changes. Data are stored in a consistent format together with the related meta-information necessary for their understanding. With its graphical user interface and the standardized import and export routines PANGAEA is a universal system which can be used easily and which is unique so far. The data model of PANGAEA enables the user to start comprehensive retrievals and to extract the retrieved data sets for specific requirements. The export of individually configured collections of meta-data, analytical data, proxy data and paleoclimatic parameters can enhance the collaboration between scientists producing proxy data and scientist using those data in models. Access on published data is ensured via a WWW-interface. The network concept, providing access through the Internet, allows the build-up of a data exchange and communication network for different institutes working on the same library of data sets. PANGAEA will allow a more efficient evaluation and interpretation of the comprehensive data sets produced in today's research projects and thus will provide a new scientific tool for solving problems to improve our understanding of Earth system dynamics.

\section{Acknowledgments}

This project was financed by the German Ministry of Education, Science, Research and Technology (BMBF), Fund No: 03F0131B (PaläoklimaDatenzentrum). The authors are indebted to Björn Grieger and an anonymous reviewer for improving the manuscript. This is Publication No. 1320 of the Alfred Wegener Institute for Polar and Marine Research and Contribution No. 175 of the Sonderforschungsbereich 261 at Bremen University. Detailed information on PANGAEA is available on request through the email 'info@pangaea.de'. Data and tools can be accessed through: http://www.pangaea.de.

\section{References}

Emiliani C(1955) Pleistocene temperatures. J Geol 63: 538-578

Grobe H, Mackensen A (1992) Late Quaternary climatic cycles as recorded in sediments from the Antarctic continental margin. In: Kennett JP, Warnke DA (eds) The Antarctic Paleoenvironment: A Perspective on Global Change. AGU, Antarctic Research Series, pp 349-376

Houston WH (1980) The Agulhas current during the late Pleistocene: analysis of modern faunal analogs. Science 207: 64-66

Imbrie J, Kipp NG (1971) A new micropaleontological method for quantitive paleoclimatology: application to a late Pleistocene Caribbean core. In: Turekian K (ed) The late Cenozoic glacial ages. Yale University Press, New Haven, pp 71-181

Imbrie J, Purdy EG (1962) Classification of modern Bahamian carbonate sediments. Mem Assoc Petr Geol I: 253-272

IOC (1994) Supporting volume to the 'GEBCO Digital Atlas' published on behalf of the Intergovernmental Oceanographic Commission and the International Hydrographic Organization as part of the General Bathymetric Chart of the Oceans (GEBCO). British Oceanographic Data Centre, Birkenhead with CD-ROM

Levitus S, Boyer T (1994) World Ocean Atlas 1994 Volume 4: Temperature. NOAA Atlas NESDIS 4, US Dept of Commerce, Washington DC 
Levitus S, Conkright ME, Gelfeld RD, Boyer T (1995) World Ocean Atlas 1994. IGBP Newsletter 20: 4-6

Lorenz S, Grieger B, Helbig P, Herterich K (1996) Investigating the sensitivity of the Atmospheric Gerneral Circulation model ECHAM 3 to paleoclimatic boundary conditions. Geol Rundsch 85: 513-524

Moore C (1995) Index to marine and geological samples. National Geophysical Data Center, World Data Center A for Marine Geology and Geophysics CD (pre-release)

Niebler H-S (1995) Rekonstruktionen von PaläoUmweltparametern anhand von stabilen Isotopen und Faunen-Vergesellschaftungen planktischer Foraminiferen im Südatlantik. Ber Polarforsch Bremerhaven 167, pp 1-198
Pflaumann U, Duprat J, Pujol C, Labeyrie LD (1996) SIMMAX: A modern analog technique to deduce Atlantic sea surface temperatures from planktonic foraminifera in deep-sea sediments. Paleoceanography 11(1): 15-35

Schlitzer R (1997) Ocean-Data-View, http://www.awibremerhaven.de/GPH/ODV/

Webb RS, Anderson DM, Overpeck JT (1994) Archiving data at the World Data Center-A for Paleoclimatology. Paleoceanography 9(3): 391-939 
